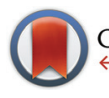

CrossMark

Cite this: Food Funct., 2016, 7, 1401

\title{
Formation of reactive aldehydes (MDA, HHE, HNE) during the digestion of cod liver oil: comparison of human and porcine in vitro digestion models
}

\author{
Cecilia Tullberg, ${ }^{\text {a }}$ Karin Larsson, ${ }^{a}$ Nils-Gunnar Carlsson, ${ }^{a}$ Irene Comi, \\ Nathalie Scheers, ${ }^{a}$ Gerd Vegarud ${ }^{\mathrm{b}}$ and Ingrid Undeland ${ }^{\mathrm{a}}$
}

In this work, we investigated lipid oxidation of cod liver oil during gastrointestinal (Gl) digestion using two types of in vitro digestion models. In the first type of model, we used human Gl juices, while we used digestive enzymes and bile from porcine origin in the second type of model. Human and porcine models were matched with respect to factors important for lipolysis, using a standardized digestion protocol. The digests were analysed for reactive oxidation products: malondialdehyde (MDA), 4-hydroxy-trans-2nonenal (HNE), and 4-hydroxy-trans-2-hexenal (HHE) by liquid chromatography/atmospheric pressure chemical ionization-mass spectrometry (LC/APCI-MS), and for free fatty acids (FFA) obtained during the digestion by gas chromatography-mass spectrometry (GC-MS). The formation of the oxidation products MDA, HHE, and HNE was low during the gastric digestion, however, it increased during the duodenal digestion. The formation of the oxidation products reached higher levels when digestive juices of human origin were used (60 $\mu \mathrm{M}$ of MDA, $0.96 \mu \mathrm{M}$ of $\mathrm{HHE}$, and $1.6 \mu \mathrm{M}$ of $\mathrm{HNE}$ ) compared to when using enzymes and bile of porcine origin $(9.8$, and $0.36 \mu \mathrm{M}$ of MDA; 0.16 , and $0.026 \mu \mathrm{M}$ of $\mathrm{HHE} ; 0.23$, and $0.005 \mu \mathrm{M}$ of $\mathrm{HNE}$, respectively, in porcine models I and II). In all models, FFA release was only detected during the intestinal step, and reached up to $31 \%$ of total fatty acids (FA). The findings in this work may be of importance when designing oxidation oriented lipid digestion studies.

Received 4th November 2015 Accepted 18th January 2016

DOI: $10.1039 / c 5 f o 01332 a$

www.rsc.org/foodfunction
(FA). ${ }^{18,19}$ Fish oil generally contains both LC n-3 and LC n-6 PUFA, with LC n-3 PUFA being paramount. However, the levels of LC n-3 and n-6 PUFA are highly varying in marine foods, e.g. depending on the fish species, feed, ${ }^{20}$ and seasonal variations. ${ }^{21}$ Marine LC n-6 PUFA are likewise known to be susceptible to oxidation, hence are also of interest when studying lipid oxidation of fish oil.

The possibility that the gastrointestinal (GI) tract is an environment enhancing lipid oxidation was suggested in the beginning of the $21^{\text {st }}$ century. ${ }^{22,23}$ We and other authors have since then revealed that fish lipids can be oxidized under GI conditions in in vitro studies, when using digestive enzymes of porcine and fungal origin. ${ }^{24,25}$ Oxidative and pro-inflammatory responses have also been shown when corresponding digests were added to yeast, Saccharomyces cerevisiae ZIM 2155, and human dendritic cells. ${ }^{26}$ That lipid oxidation can take place during the digestion of dietary lipids has also been supported in vivo in a study using mini-pigs. ${ }^{27}$ Lipid oxidation has additionally been found to occur when human gastric juice (HGJ) was used in in vitro model digestion of herring oil. ${ }^{28}$ However, to our knowledge, no two-step in vitro digestion, including both a gastric and a duodenal step, with human GI juices has been used to study oxidation of marine lipids previously.

\footnotetext{
${ }^{a}$ Department of Biology and Biological Engineering, Food and Nutrition Science, Chalmers University of Technology, Gothenburg, Sweden.

E-mail: cecilia.tullberg@chalmers.se

${ }^{b}$ Department of Chemistry, Biotechnology and Food Science, Norwegian University of Life Science, Ås, Norway
} 
The lipid oxidation reaction is known to generate highly reactive oxidation products that may negatively interact e.g. with DNA and proteins, leading to the dysfunction of cells. Some of these reactive oxidation products are the $\alpha, \beta$-unsaturated aldehydes malondialdehyde (MDA), 4-hydroxy-trans-2hexenal (HHE), and 4-hydroxy-trans-2-nonenal (HNE), ${ }^{29}$ see Fig. 1. The extensively studied molecule MDA has previously been in focus as an unspecific biomarker of lipid oxidation and as a molecule with possible negative effects on health. ${ }^{30}$ MDA has been suggested to possess carcinogenic and genotoxic properties, and has additionally been linked with toxicity towards the cardiovascular system. ${ }^{30}$ It has been shown that MDA can be derived from several different precursor molecules, but the main origin is PUFA, and MDA is strongly linked to lipid oxidation in biological matrixes. ${ }^{30} \mathrm{HNE}$ and to some extent HHE, have also caught attention as toxic marker molecules for lipid oxidation, HHE as an aldehyde derived from $n-3$ PUFA, ${ }^{31,32}$ and HNE from n-6 PUFA. ${ }^{31,33}$ Both HHE and HNE have been shown to be cytotoxic, genotoxic, and carcinogenic in biological systems, and react in a similar way since they are both hydroxyalkenals. ${ }^{29}$ However, there are some differences in the specific targets when HHE and HNE react with proteins, and there are additional differences in the metabolic pathways of HHE and HNE. ${ }^{34}$ This emphasises the detection of both the hydroxyalkenals as biomarkers for lipid oxidation. Since both n-3 PUFA and n-6 PUFA are found in fish oils, the formation of HHE and HNE is of importance when studying lipid oxidation in marine matrixes. However, little is known about the extent of MDA, HHE, and HNE formation in the human GI tract during the digestion of marine foods and supplements. In a recent study, the effect of a diet with oxidized lipids was assessed in mice, and it was found that the plasma levels of HHE accumulated over time. ${ }^{35}$ In the same study, the absorption of HHE and the formation of protein adducts in the small intestine of mice were observed, following the administration of HHE, indicating that HHE can be absorbed, but also that it may cause local damage in the GI tract. ${ }^{35}$ Kenmogne-Domguia et al. ${ }^{36}$ recently investigated lipid oxidation of stabilized marine oil emulsions, containing a mixture of tuna oil, oleic sunflower oil, and sunflower oil, during in vitro digestion using porcine enzymes. They found that both oxygen uptake and MDA formation increased over digestion time and that the highest levels were found in the intestinal phase. ${ }^{36}$ Detecting levels of the three reactive aldehydes MDA, HHE, and HNE simultaneously in digests of fish oil would give insights into the potential toxicity caused by the oxidation in the GI tract. MDA in marine oil has commonly been monitored together with other carbonyls as part of the thiobarbituric acid reactive substance (TBARS) test, ${ }^{24,36}$ or with high-performance liquid chromatography (HPLC). ${ }^{37}$ Analysis of accumulated HHE and HNE in fish or vegetable oil has commonly been done by GC-MS. ${ }^{36,38}$ According to the literature, ${ }^{39}$ liquid chromatography/atmospheric pressure chemical ionization-mass spectrometry (LC/APCI-MS) should allow their separation and detection in one run.

In vitro digestion models of today are usually based on enzymes and bile of porcine origin, either as extracts of bile and/or pancreatin, or as pure enzymes. ${ }^{40}$ The use of human GI juices for in vitro digestion studies is however uncommon. It has previously been shown that peptides derived from the digestion of whey proteins with human GI juices differ from those formed during digestion with enzymes and bile of porcine origin. ${ }^{41}$ The differences observed might be due to the specificities of the GI enzymes or other conditions used. It has not been thoroughly studied how human and porcine-based in vitro digestion models differ when it comes to levels and types of pro- or anti-oxidants, which could highly influence the outcome of the oxidation-oriented lipid digestion studies. In response to a high variability of porcine-based in vitro digestion models, a standardized static in vitro digestion model was developed through the COST Action project InfoGest. ${ }^{40}$ This was done in order to harmonize different protocols, and thus researchers are able to compare different digestion studies. This study was conducted during the development of the InfoGest protocol and is therefore highly influenced by it.

The aim of this study was to compare the formation of reactive lipid oxidation products of cod liver oil during digestion using an in vitro model based on human digestive juices, and digestive models comprising enzymes and bile of porcine origin. The lipolytic release of free fatty acids (FFA) was additionally compared between the models. To confirm that the digestion models were properly matched, the enzyme activities were monitored. The formation of the reactive lipid oxidation-derived aldehydes MDA, HHE, and HNE was analysed using a combined applied LC/APCI-MS method.

\section{Materials and methods}

\section{Chemicals}

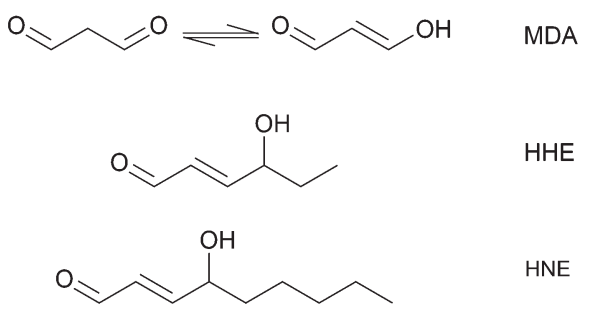

Fig. 1 Chemical structure of malondialdehyde (MDA), 4-hydroxy-trans2-hexenal (HHE), and 4-hydroxy-trans-2-nonenal (HNE).
Pepsin from porcine gastric mucosa $\left(655 \mathrm{U} \mathrm{mg}^{-1}\right.$, Fluka77163), pancreatin from porcine pancreas $(4 \times$ USP, SigmaP1750), and porcine bile extract (Sigma-B8631) were obtained from Sigma Aldrich (Saint Louis, USA). HHE and HNE were purchased from Cayman (Ann Arbor, USA). A Milli-Q plus system (Merck Millipore, Darmstadt, Germany) was used to purify water to a minimum resistance of $18.2 \mathrm{M} \Omega \mathrm{cm}$. All other chemicals, such as solvents used, were at least of analytical grade. 


\section{Samples}

The sample used in the digestion studies was refined cod liver oil. The oil did not contain any added antioxidants and was supplied by Lýsi hf (Reykjavík, Iceland). Expressed as peak area (\%) of the detected total FA methyl esters (FAME), the oil contained 24.4\% n-3 PUFA (8.2\% EPA and 10.5\% DHA), and 1.3\% n-6 PUFA. ${ }^{42}$ In total it contained $27.5 \%$ PUFA, $48 \%$ MUFA, and $17.2 \% \mathrm{SFA}^{42}$ (Table 1). Human gastric juice (HGJ) and human duodenal juice (HDJ) were aspirated from four and five volunteers, respectively, as described by Ulleberg et $a l^{43}$ and Holm et l. $^{44}$ The volunteers were healthy and semi-fasting. In short, a triple lumen tube (Maxter Catheters, Marseille, France) was used for the aspiration of digestive juices, and was placed in the correct position of the volunteer by gastroscopy. A stimulatory solution was introduced by the tube $\left(100 \mathrm{~mL} \mathrm{~h}^{-1}\right)$, while the aspirates were collected close to the papilla of Vater in the duodenum, and from the canalis ventriculi in the stomach. The $\mathrm{pH}$, volume, and enzyme activities of the aspirates from the stomach and the duodenum were assayed. Individual aspirates were pooled to eliminate individual effects as much as possible, and the samples were stored at $-80{ }^{\circ} \mathrm{C}$. The aspirations were carried out at Lovisenberg Diakonale Hospital, Oslo, Norway, from June to September 2013. The study was performed with approval from the Norwegian Regional Ethics Committee (project no. 2012/2230, Biobank no. 2012/2210). The Declaration of Helsinki was followed, and all participants in the study signed up as volunteers with informed consent.

Table 1 Fatty acid composition of cod liver oil from Lýsi hf. Results are expressed in peak area (\%) of total fatty acid methyl esters (FAME), $n=$ 2. EPA, eicosapentaenoic acid; DPA, docosapentaenoic acid; DHA, docosahexaenoic acid; SFA, saturated fatty acids; MUFA, monounsaturated fatty acids; PUFA, polyunsaturated fatty acids. Table reprinted from Jónsdóttir et al. ${ }^{42}$ with permission from John Wiley and Sons

\begin{tabular}{|c|c|c|}
\hline FAME & $\begin{array}{l}\text { Area } \\
(\%)\end{array}$ & $\begin{array}{l}\text { Conc. of lipids } \\
\left(\mathrm{mg} \mathrm{g}^{-1}\right)\end{array}$ \\
\hline C14:0 & 3.9 & 41 \\
\hline C16:0 & 10.4 & 112 \\
\hline C16:1n-7 & 6.3 & 67 \\
\hline C16:2n-4 & 0.7 & 7 \\
\hline C18:0 & 2.2 & 24 \\
\hline C18:1n-11 & 2.2 & 24 \\
\hline C18:1n-9 & 13.9 & 149 \\
\hline C18:1n-7 & 4.1 & 44 \\
\hline C18:2n-6 & 1.3 & 14 \\
\hline C18:3n-3 & 0.7 & 8 \\
\hline C20:1n-11 & 1.9 & 21 \\
\hline C20:1n-9 & 9.4 & 102 \\
\hline C20:1n-7 & 0.5 & 6 \\
\hline C18:4n-3 & 2.0 & 21 \\
\hline C22:1n-9 & 8.3 & 91 \\
\hline$C 20: 3 n-3$ & 1.1 & 12 \\
\hline C20:4n-3 & 0.7 & 8 \\
\hline C20:5n-3 (EPA) & 8.2 & 89 \\
\hline C22:5n-3 (DPA) & 1.2 & 13 \\
\hline C22:6n-3 (DHA) & 10.5 & 114 \\
\hline Sum SFA & 17.2 & - \\
\hline Sum MUFA & 48.0 & - \\
\hline Sum PUFA & 27.5 & - \\
\hline
\end{tabular}

\section{Characterization of human juices}

Factors important for lipolysis were analysed and compared when using the two digestion models. The chosen factors were: pancreatic lipase activity, bile-salt concentration, and calcium ion concentration. Pancreatic lipase contributes to a major part of the lipolysis in the body, ${ }^{45}$ while bile-salt is needed for micelles to form in the small intestine. Bile-salt additionally affects lipolysis by inhibiting pancreatic lipase in the absence of co-lipase. ${ }^{45}$ Ionic calcium enhances the activity of e.g. pancreatic phosphatide 2 -acylhydrolase, ${ }^{45}$ and at high concentrations also causes soap formation, precipitating the FFA, calcium, and bile salt together. ${ }^{46}$

The total protein concentration was initially measured to standardize the porcine model I and human model against each other, since the total protein levels detected in the HGJ and HDJ were related to the concentrations of enzymes added in the porcine model I (see the section "In vitro static digestion models"). Haemoglobin and trace metal ions were analysed in the human juices, since they are potent pro-oxidants. ${ }^{47,48}$ Measurements to characterize the human juices were carried out in triplicate, unless otherwise stated.

Pancreatic lipase activity. Pancreatic lipase activity was assayed in HDJ at the time of collection (day 2) and after 11 months of storage at $-80{ }^{\circ} \mathrm{C}$. This was done according to Ulleberg et al. ${ }^{43}$ by using a colorimetric assay kit, LIP (Roche Diagnostics $\mathrm{GmbH}$, Mannheim, Germany), using 1,2-Odilauryl-rac-glycero-3-glutaric acid-(6-methylresorufin) as the substrate, which is a non-diglyceride chromogenic substrate. Lipase activity was additionally measured using a titrimetric protocol described by Minekus et al. ${ }^{40}$ Pancreatic lipase activity in $\mathrm{HDJ}$ was calculated in $\mathrm{U} \mathrm{mL}^{-1}$ using tributyrin as the substrate.

Total protein concentration. Total protein concentrations in HGJ and HDJ were analysed using a Qubit Fluorometer in combination with a Quant-ITTM protein assay kit (Invitrogen Co., Carlsbad, CA, USA), according to the instructions provided by the manufacturer.

Bile-salt concentrations. The bile-salt concentration in HDJ was measured using the ADVIA 1650 clinical system (Bayer Healthcare, Tarrytown, NY, USA) for automated analysis. A bile acid kit (Bio-stat Diagnostic systems, Stockport, UK) was used to spectrophotometrically $(410 \mathrm{~nm})$ determine the bile-salt concentration. The analysis was based on the formation of Thio-NADH, due to the action of the enzyme $3 \alpha$-hydroxysteroid dehydrogenase, and standardized against taurocholic acid. Measurements were carried out in duplicate at the Central Laboratory of the Norwegian School of Veterinary Science (Oslo, Norway).

Calcium ion concentration. Calcium ion concentrations in HGJ and HDJ were measured using a Dionex HPLC BioLC system (Thermo Scientific, Sunnyvale, USA) with a CG14 guard column, combined with an IonPac CS14 analytical column $(4 \times$ $250 \mathrm{~mm}$ ). The BioLC was combined with a CD20 conductivity detector, a GS50 gradient pump, and a Spark Holland autosampler (Triathlon, Sunnyvale, the Netherlands). A CMMS3 
$4 \mathrm{~mm}$ suppressor was placed before the detector. Analysis was done using $9 \mathrm{mM}$ methanesulphonic acid as a mobile phase. Samples were measured under isocratic conditions, with the flow rate $0.9 \mathrm{~mL} \mathrm{~min}^{-1}$, and $20 \mu \mathrm{L}$ per sample was injected at room temperature. Standards of $\mathrm{Ca}^{2+}$, as $\mathrm{CaCl}_{2}$, in the range 0.01-10 ppm, were used, and analysis showed linearity within this chosen region. Data collection and analysis were carried out with the help of Dionex Chromeleon software (Thermo Scientific, Sunnyvale, USA).

Analysis of trace metal ions and haemoglobin. Analysis of trace metal ions in HDJ, as well as in porcine bile and pancreatin of porcine origin was carried out according to the method by Fredrikson et al. $^{49}$ External standards for $\mathrm{Cu}, \mathrm{Ni}, \mathrm{Zn}$, Co, $\mathrm{Mn}$, and $\mathrm{Fe}$ were used. Acidic microwave digestion of the samples was followed by separation and detection on ion chromatography coupled with UV-vis spectroscopy. Total haem pigment content was analysed according to the method by Hornsey, ${ }^{50}$ using bovine haemoglobin as an external standard. Detection was done spectrophotometrically at $640 \mathrm{~nm}$.

\section{Analysis of porcine pancreatic and bile extracts}

The porcine pancreatic extract was analysed for lipase activity, using the method described by Minekus et $a l .{ }^{40}$ and recorded in $\mathrm{U} \mathrm{mg}^{-1}$. Bile-salt concentrations $(\mathrm{mM})$, ionic calcium concentrations $(\mathrm{mM})$, and total protein concentrations $\left(\mathrm{mg} \mathrm{mL} \mathrm{m}^{-1}\right)$ in the porcine-bile extracts and pancreatin were analysed in the same way as the human juices. Bile-salt concentrations were measured three times (each time $n=2$ ) in the bile extracts, due to large variations in the results. A mean value of the bile-salt concentration was used in the design of the in vitro digestion model.

\section{In vitro static digestion models}

In this study, a static in vitro digestion model with human GI juices and another with porcine enzymes and bile was used. For the first part of the study, the work in progress protocol by Minekus et al. ${ }^{40}$ was used, and this porcine model is referred to as "porcine model I". The amounts of enzymes used in the porcine model I were based on the total protein levels detected in the HGJ and HDJ, according to Aarak et al. ${ }^{51}$ This is the reason why the human model and the porcine model I differ in regard to the dilution of the initial meal, and the recorded enzyme activities, see Table 2 . Based on one of the highlighted points of the published InfoGest standardized protocol, ${ }^{40}$ enzyme activities important for lipid digestion were measured again, and from the results, a second porcine model, referred to as "porcine model II", was achieved according to the final protocol of Minekus et al. ${ }^{40}$ adjusting the porcine lipase activities, bile-salt, and calcium ion levels to the same levels as those found in human GI juices. The protocol for gastric and duodenal digestion was followed, omitting the oral salivary $\alpha$-amylase due to the lack of carbohydrates in the food matter. In all the digestion models, sampling of the digests was carried out after 10, 30, 60, and $120 \mathrm{~min}$ in the gastric step, and after 10, 30, 60, and $90 \mathrm{~min}$ in the duodenal step. Tubes with digests were stored at $-80{ }^{\circ} \mathrm{C}$ directly after sampling. A comprehensive overview of the porcine models I and II, and the human digestion model is shown in Table 2. Table 3 shows an overview of the simulated GI solutions used, based

Table 2 Digestion parameters in the gastric and intestinal step of the porcine models (I and II) and human model. n.a.: samples not analyzed

\begin{tabular}{|c|c|c|c|c|c|c|}
\hline Digestion parameters & $\begin{array}{l}\text { Porcine model I } \\
\text { stomach }\end{array}$ & $\begin{array}{l}\text { Porcine model I } \\
\text { duodenum }\end{array}$ & $\begin{array}{l}\text { Porcine model II } \\
\text { stomach }\end{array}$ & $\begin{array}{l}\text { Porcine model II } \\
\text { duodenum }\end{array}$ & $\begin{array}{l}\text { Human } \\
\text { stomach }\end{array}$ & $\begin{array}{l}\text { Human } \\
\text { duodenum }\end{array}$ \\
\hline Dilution of the initial meal (oil + water) & $1: 2$ & $1: 6$ & $1: 2$ & $1: 15$ & $1: 2$ & $1: 15$ \\
\hline Lipase activity ${ }^{a}\left(\mathrm{U} \mathrm{mL}^{-1}\right)$ & n.a. & $23^{d}$ & n.a. & n.a., $570^{d}$ & n.a. & 570 and $190^{c}$ \\
\hline Lipase activity $^{b}\left(\mathrm{U} \mathrm{mL}^{-1}\right)$ & n.a. & 17 & n.a. & 510 & n.a. & $140^{c}$ \\
\hline Bile-salt conc. (mM) & n.a. & 4.7 & n.a. & 2.6 & n.a. & 2.6 \\
\hline $\mathrm{Ca}^{2+}$ conc. $(\mathrm{mM})$ & 1.46 & 0.63 & 0.32 & 0.34 & 0.32 & 0.34 \\
\hline
\end{tabular}

${ }^{a}$ The lipase activity measured by the colorimetric method described by Ulleberg et al. ${ }^{43}{ }^{b}$ The lipase activity measured by the titrimetric method described by Minekus et al. ${ }^{40}{ }^{c}$ Measured after 11 months of storage at $-80{ }^{\circ} \mathrm{C}$. ${ }^{d}$ Calculated with a conversion factor between the (a) and (b) lipase activity methods. ${ }^{e}$ Calculated according to $\mathrm{mg}$ enzyme per $\mathrm{mL}$ added to the digestion model, assuming that all proteins detected were enzymes.

Table 3 Simulated Gl solutions used in the porcine models I and II. pH was adjusted by adding sodium hydroxide ( $\mathrm{NaOH})(1 \mathrm{M})$, sodium bicarbonate $\left(\mathrm{NaHCO}_{3}\right)(0.15 \mathrm{M})$, and hydrochloric acid $(\mathrm{HCl})(1 \mathrm{M})$. Calcium $\left(\mathrm{CaCl}_{2}\left(\mathrm{H}_{2} \mathrm{O}\right)_{2}\right)$ was added later into the digestion model

\begin{tabular}{|c|c|c|c|c|c|c|c|c|}
\hline $\begin{array}{l}\text { Simulated GI } \\
\text { solution }\end{array}$ & $\begin{array}{l}\mathrm{KCl} \\
(\mathrm{mM})\end{array}$ & $\begin{array}{l}\mathrm{KH}_{2} \mathrm{PO}_{4} \\
(\mathrm{mM})\end{array}$ & $\begin{array}{l}\mathrm{NaHCO}_{3} \\
(\mathrm{mM})\end{array}$ & $\begin{array}{l}\mathrm{NaCl} \\
(\mathrm{mM})\end{array}$ & $\begin{array}{l}\mathrm{MgCl}_{2}\left(\mathrm{H}_{2} \mathrm{O}\right)_{6} \\
(\mathrm{mM})\end{array}$ & $\begin{array}{l}\left(\mathrm{NH}_{4}\right)_{2} \mathrm{CO}_{3} \\
(\mathrm{mM})\end{array}$ & $\mathrm{pH}$ & $\begin{array}{l}\mathrm{CaCl}_{2}\left(\mathrm{H}_{2} \mathrm{O}\right)_{2} \\
(\mathrm{mM})\end{array}$ \\
\hline Gastric, porcine I & 35 & 0.9 & 13 & 41.1 & 0.6 & - & 3 & 0.4 \\
\hline Duodenal, porcine I & 6.8 & 0.8 & 85 & 32.9 & 0.33 & - & 7 & 0.4 \\
\hline Gastric, porcine II & 6.9 & 0.9 & 25 & 47.2 & 0.1 & 0.5 & 3 & 0.4 \\
\hline Duodenal, porcine II & 6.8 & 0.8 & 85 & 38.4 & 0.33 & - & 7 & 0.4 \\
\hline
\end{tabular}


on the work in progress protocol (porcine model I), and the final protocol (porcine model II) of Minekus et al. ${ }^{40}$ Control samples of only human juices or porcine enzymes diluted in the simulated gastric/duodenal solutions were included in the digestion models and collected at 120 and $210 \mathrm{~min}$ for the gastric and the duodenal step, respectively.

In vitro digestion, porcine models I and II. The digestion model set up included oil mixed with water $\left(0.13 \mathrm{mg} \mathrm{mL}^{-1}\right)$ as the initial meal. The samples were flushed with $\mathrm{N}_{2}$ gas for $20 \mathrm{~s}$. The ratio between the initial food and the digestive steps followed the standardized protocol by Minekus et al. ${ }^{40}$ For the gastric phase pepsin $\left(0.45 \mathrm{mg} \mathrm{mL}^{-1}\right.$ in the final gastric step) was added to simulate the gastric fluid, and in addition $\mathrm{CaCl}_{2}\left(\mathrm{H}_{2} \mathrm{O}\right)_{2}(1.5 \mu \mathrm{L}, 0.4 \mathrm{M})$ simulated the gastric solution (Table 3), and water was added to the initial meal. The $\mathrm{pH}$ was adjusted to $\mathrm{pH} 3$ by adding $\mathrm{HCl}(1 \mathrm{M})$. During the gastric step, the tubes were kept in the dark $\left(37^{\circ} \mathrm{C}, 50 \mathrm{rpm}\right)$. After the gastric step (120 min), $\mathrm{CaCl}_{2}\left(\mathrm{H}_{2} \mathrm{O}\right)_{2}(3 \mu \mathrm{L}, 0.4 \mathrm{M})$, simulated duodenal solution (Table 3$)$ with porcine bile $\left(20 \mathrm{mg} \mathrm{mL}^{-1}\right)$ and pancreatin $\left(2.4 \mathrm{mg} \mathrm{mL} \mathrm{m}^{-1}\right)$, and water was added to the samples. The $\mathrm{pH}$ was corrected to $\mathrm{pH} 7$ by adding $\mathrm{NaOH}(1 \mathrm{M})$ and $\mathrm{NaHCO}_{3}(0.15 \mathrm{M})$. During the duodenal step, the tubes were kept in the dark $\left(37^{\circ} \mathrm{C}, 250 \mathrm{rpm}\right)$. Porcine model II was modified to match the human model based on lipase activity, bile-salt, and ionic calcium concentration, as well as the dilution of the initial meal, see Table 2 . Other than this, the porcine model II followed the same procedure as model I.

In vitro digestion, human digestion model. The human digestion model followed the same procedures as the porcine models, with respect to oxygen reduction, incubation intervals, mixing rate, sampling etc. HGJ $(0.8 \mathrm{~mL})$ was added to cod liver oil and water, the $\mathrm{pH}$ was adjusted to 3 by the addition of $\mathrm{NaHCO}_{3}(0.15 \mathrm{M})$, and the samples were kept in the dark $\left(37^{\circ} \mathrm{C}, 50 \mathrm{rpm}\right)$. HDJ $(6.4 \mathrm{~mL})$ was added and the $\mathrm{pH}$ adjusted to 7 by adding $\mathrm{NaOH}(1 \mathrm{M})$ before further incubation $\left(37^{\circ} \mathrm{C}\right.$, $250 \mathrm{rpm}$ ), and sampling at regular intervals for $90 \mathrm{~min}$.

\section{Lipid extraction and analysis of free fatty acids (FFA)}

Lipid extraction. Lipids were extracted from the undigested (control) and digested samples (gastric and duodenal) according to Bligh and Dyer, ${ }^{52}$ with modifications according to Lee et $a .^{53}$ Throughout the procedure, the samples were covered with aluminium foil and kept on ice in order to prevent oxidation. The fatty acid heptadecanoic acid (C17:0), was added from the start to all samples as an internal standard. Due to large sample volumes, separation funnels (size 50-200 mL) were used for the extraction of samples from the gastric and duodenal steps of the human model and porcine model II. All other samples were extracted in glass tubes $(15 \mathrm{~mL}) . \mathrm{CHCl}_{3}-$ $\mathrm{MeOH}$ in ratios $2: 1$ and $1: 2$, was used in the high-fat (fat content $>6 \%$ ) and low-fat (fat content $<2 \%$ ) samples, respectively, and $0.05 \%(\mathrm{w} / \mathrm{v})$ butylated hydroxytoluene (BНT) was added to the samples $(10: 1)$. After mixing, $\mathrm{NaCl}(0.5 \%)$ was added $(1: 2.75)$. The tubes were then vortexed $(10 \mathrm{~s})$ and the separation funnels were turned $3 \times 2$ times and shaken $(10 \mathrm{~s})$. The tubes were then centrifuged $(3000 \mathrm{~g}, 6 \mathrm{~min})$ and the separ- ation funnels were kept in a cold room $\left(4^{\circ} \mathrm{C}\right)$ until phase separation had occurred. The chloroform phase was withdrawn and evaporated to dryness $\left(\mathrm{N}_{2}\right.$ gas, $\left.40^{\circ} \mathrm{C}\right)$.

Analysis of FFA. Lipids were dissolved in a small volume of chloroform before loading on Telos $\mathrm{NH}_{2}$ SPE-columns (500 mg per $6 \mathrm{~mL}$ ) (Kinesis, St Neots, UK). Lipid classes (neutral lipids, phospholipids and FFA) were separated according to Kaluzny et $a l .{ }^{54}$ Heneicosanoic acid (C21:0) was used as an additional standard to study losses during the solid phase extraction (SPE). The FFA fraction was collected, the solvent $\left(\mathrm{CHCl}_{3}\right)$ was evaporated to dryness $\left(\mathrm{N}_{2}\right.$ gas, $\left.40^{\circ} \mathrm{C}\right)$ and FFA were methylated by the in-house methanolic-HCl transesterification method described by Cavonius et al. ${ }^{55}$ The following modifications were applied: toluene $(2 \mathrm{~mL})$ was added to the lipid residues, followed by the addition of $10 \%(\mathrm{v} / \mathrm{v}) \mathrm{MeOH}$ : acetylchloride $(2 \mathrm{~mL})$; the samples were methylated at $60{ }^{\circ} \mathrm{C}$, for $150 \mathrm{~min}$, whereafter the reaction was terminated by water $(1 \mathrm{~mL})$. Petroleum ether $(2 \mathrm{~mL})$ was then added to extract the FFA. The samples were vortexed and centrifuged $(2500 \mathrm{~g}, 5 \mathrm{~min})$ and the organic phase was analysed using GC-MS according to Cavonius et $a l^{55}$ with the external fatty acid standard mix GLC 463 (Nu-Chek Prep, Inc., Elysian, USA).

Analysis of total fatty acids (FA). Total FA were methylated and analysed in the same way as the FFA, but without separation on SPE-columns into lipid classes. FA methyl esters were then detected as FAME.

\section{Determination of HHE, HNE, and MDA}

Non-protein bound lipid oxidation products HHE, HNE, and MDA were analysed by 2,4-dinitrophenylhydrazine (DNPH) (Brady's reagent) derivatization of aldehydes and LC/APCI-MS analyses by a method developed from the analytical principles described by Grosjean et al., ${ }^{39}$ Deighton et al., ${ }^{56}$ Andreoli et $a .^{57}$ and Sakai et $a l .{ }^{58}$ Undigested samples (control), digested samples (gastric and duodenal) and standards were mixed with BHT (1:25 BHT to sample, 4.5 $\mathrm{M}$ in $\mathrm{MeOH}$ ) and ethylenediaminetetraacetic acid (EDTA) disodium salt (1:13 EDTA to sample, $0.02 \mathrm{M}$ ). Acidification was carried out with $\mathrm{HCl}(1: 1.12,0.25 \mathrm{M})$ and the samples were vortexed and left for precipitation for $5 \mathrm{~min}$.

After precipitation, the samples were centrifuged $(16000 g$, $2 \mathrm{~min})$ and $\mathrm{DNPH}(25 \mu \mathrm{L}, 10 \mathrm{mM}$ in $\mathrm{MeOH})$ was added to the supernatant $(0.4 \mathrm{~mL})$, before vortexing and incubation $\left(25^{\circ} \mathrm{C}\right.$, $60 \mathrm{~min})$. Two extractions were then carried out with dichloromethane $(0.5 \mathrm{~mL})$, during which the samples were vortexed (10 s) and centrifuged (16 000g, $2 \mathrm{~min}$ ) before the lower phase was transferred into new tubes. The samples were evaporated to dryness $\left(\mathrm{N}_{2}\right.$ gas, $25^{\circ} \mathrm{C}$ ) and the residues diluted in $\mathrm{MeOH}$ $(0.25 \mathrm{~mL})$, vortexed and centrifuged $(16000 \mathrm{~g}, 2 \mathrm{~min})$, and the supernatants were transferred into vials.

Stocks of HNE ( $1 \mathrm{mg}$ in $100 \mu \mathrm{L}$ EtOH$)$, and HHE $(1 \mathrm{mg}$ in $100 \mu \mathrm{L} \mathrm{MeOH})$ were used as external standards for HNE and HHE, and 1,1,3,3-tetraethoxypropane (TEP) (1 mM), hydrolysed in $\mathrm{H}_{2} \mathrm{SO}_{4}(1 \%)\left(25{ }^{\circ} \mathrm{C}, 120 \mathrm{~min}\right)$, was used as an external standard for MDA. Concentrations of the stock solutions were determined spectrophotometrically $\left(\lambda_{\mathrm{MDA}}=245 \mathrm{~nm}\right.$, 
$\varepsilon_{\mathrm{MDA}}$ in acidic $\mathrm{H}_{2} \mathrm{O}=13700 ; \lambda_{\mathrm{HHE}}=219 \mathrm{~nm}, \varepsilon_{\mathrm{HHE}}$ in $\mathrm{MeOH}=$ $13750 ; \lambda_{\mathrm{HNE}}=221 \mathrm{~nm}, \varepsilon_{\mathrm{HNE}}$ in EtOH $\left.=16000\right)$. External standard mixtures with different concentrations of MDA, HHE, and HNE were included in each sequence in the LC/APCI-MS.

The analysis was performed on an Agilent 1260 HPLC system, consisting of a binary pump, an auto sampler, a column oven, and an UV-detector, coupled to an Agilent 6120 quadrupole in the APCI negative mode (Agilent Technologies, Waldbron, Germany). The separation was performed on a Phenomenex Luna, $4.6 \mathrm{~mm}$ i.d. $\times 250 \mathrm{~mm}, 3 \mu \mathrm{m}$, C18 columns (Phenomenex, Macclesfield, UK), at a flow rate of $0.7 \mathrm{~mL}$ $\min ^{-1}$ and injection volume of $15 \mu \mathrm{L}$, using a gradient at $50{ }^{\circ} \mathrm{C}$. Analysis of the data was carried out using the Agilent ChemStation (Agilent Technologies, Böblingen, Germany) software program. $\mathrm{N}_{2}$ gas was used for nebulisation (40 psig), drying was carried out at $350^{\circ} \mathrm{C}$, and vaporization was carried out at $450{ }^{\circ} \mathrm{C}$, all other MS conditions were set according to Grosjean et al. ${ }^{39}$

The mobile phases were: A: $\mathrm{MeOH}$, with $20 \mathrm{mM} \mathrm{HAc}$, and B: water, with $20 \mathrm{mM}$ HAc. A gradient program was followed for $40 \mathrm{~min}$, which started with A (70\%) and B (30\%) in $2 \mathrm{~min}$, then A increased linearly to $95 \%$ over $8 \mathrm{~min}$. $95 \%$ of eluent A and $5 \%$ of $\mathrm{B}$ were then maintained for $10 \mathrm{~min}$. Another linear increase started at $20 \mathrm{~min}$ and continued for $5 \mathrm{~min}$ to reach $98 \%$ of eluent A and $2 \%$ of eluent B. This setting was maintained for $2 \mathrm{~min}$, then eluent A was reduced linearly to $70 \%$ over $1 \mathrm{~min} .70 \%$ of eluent A and $30 \%$ of eluent B were maintained until the end of the gradient program.

Data acquisition was carried out in selected ion monitoring (SIM) modes, and the ions were collected at 234.0, 293.1, and $335.1 \mathrm{~m} / \mathrm{z}$ at fragmentor settings 50, 150, and 170, respectively. UV detection was performed at $264 \mathrm{~nm}$, to confirm the analysis.

Validation of the method showed that the inter-day variation was $0.99 \%$ (standard deviations) of MDA, $2.1 \%$ of $\mathrm{HHE}$, $1.2 \%$ of HNE. Linearity was controlled for: MDA, $R^{2}=0.985$ (0.025-100 $\mu \mathrm{M})$, HHE, $R^{2}=0.997(0.01-10 \mu \mathrm{M})$, and HNE, $R^{2}=$ $0.997(0.005-10 \mu \mathrm{M})$. Limit of quantification is defined as a signal-to-noise ratio above 10. Between day variation and repeatability in digested samples was within $10 \%$ for all aldehydes.

\section{Statistics}

Statistical analysis of the data was performed using IBM SPSS statistics version 22 (IBM Corporation, New York, USA). Differences between the human and the porcine models were determined by using two-tailed Student's $t$-test. Unequal variance was assumed and the significance level was $p=0.05$.

\section{Results and discussion}

The scope of this study was to analyse and compare lipid oxidation of cod liver oil during digestion in two types of static in vitro digestion models. The porcine models I and II were based on porcine bile and GI commercial enzymes; commonly used when studying digestion, and the human model was based on human GI juices. The lipid oxidation products analysed were the aldehydes MDA, HHE, and HNE. The results from the development of the in vitro GI digestion models and from analyses of lipolysis and oxidation during digestion are presented below.

\section{In vitro digestion based on human GI juices and GI commercial enzymes}

To adjust the porcine model II to the human model, important factors for lipolysis were analysed and compared. An overview of these different factors is shown in Table 2. The bile-salt concentration in the pooled human duodenal juice $(2.6 \mathrm{mM})$ was low compared to what is recommended in the standard protocol. ${ }^{40}$ This is probably due to the 12 hours fasting of the volunteers prior aspiration. In a review by McConnell et al. ${ }^{59}$ the bile-salt output in the food stimulated state is reported to be $11 \mathrm{mM}$. The bile secretion is activated by the ingestion of food, and in a fasting state the production is fairly low $(0.6-5 \mathrm{mM}) .{ }^{59}$ Previous reports of bile-salt concentration of HDJ has been shown to be in the range between $3-5 \mathrm{mM}$ in pooled aspirated samples. ${ }^{43,60,61}$ The lipase activity of the pooled HDJ was lower than recommended in the standardized protocol, $570 \mathrm{U} \mathrm{mL}^{-1}$ versus $2000 \mathrm{U} \mathrm{mL}{ }^{-1} \cdot{ }^{40}$ However, it was decided to use the natural content of bile and lipase as it occurred in the human juices, and not add the commercial porcine bile or lipase.

The ionic calcium concentration in HDJ correlated quite well with the values used in the standardized protocol, $0.34 \mathrm{mM}$ versus $0.3 \mathrm{mM}^{40}$ In the pooled HGJ, higher levels were recorded than those recommended in the standardized protocol. ${ }^{40}$ To make the human and porcine models comparable, a higher ionic calcium concentration than recommended was therefore added in the gastric step of the porcine model II.

\section{Lipolysis during in vitro digestion of cod liver oil}

No FFA increase was observed during the gastric digestion in any of the static in vitro digestion models, however, during intestinal digestion lipolysis occurred in both the porcine and the human models (Fig. 2). This is in line with earlier analyses, showing that no active gastric lipase was found in either HGJ or in the porcine pepsin (data not shown). As presented in Fig. 2, the lipolysis in the duodenal step reached similar levels in the human model and porcine model II showing that the lipolysis by the pancreatic lipase was comparable in these models. The level of lipolysis after $210 \mathrm{~min}$ in the human digestion model and the porcine model II was $31 \%$ and $26 \%$, respectively, with no significant difference between the models. When comparing the human digestion model (31\%) with porcine model I (16\%), a significant difference $(p<0.005)$ was seen after the duodenal digestion $(t=210 \mathrm{~min})$. This is most probably due to differences in lipase activity that was 25fold lower in the porcine model I compared to the porcine model II and the human model. The levels of released FFA during digestion are in accordance with lipolysis levels reported in in vitro digestion of marine lipids. If expressed as $\%$ FFA release of total oil (mg), we see a $21 \%, 11 \%$ and $18 \%$ 


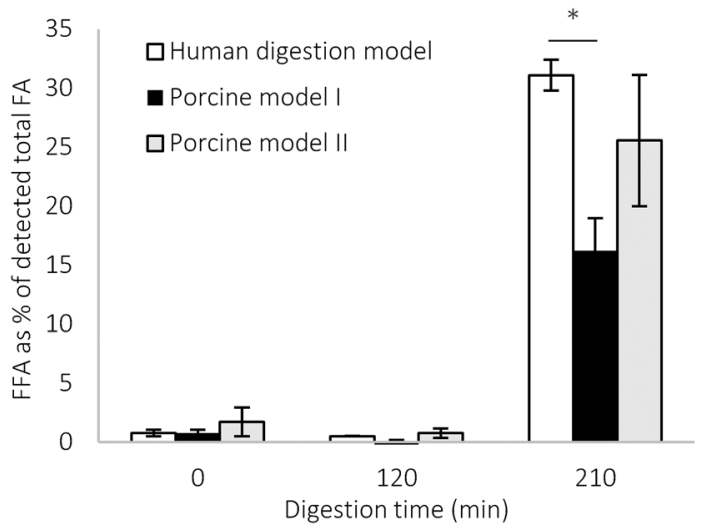

Fig. 2 Release of free fatty acids (FFA) during gastric (120 min) and duodenal $(90 \mathrm{~min}$ ) digestion of cod liver oil. Results are shown as \% of FFA per detected total fatty acids (FA) in cod liver oil. Error bars show $\mathrm{SD}, n \geq 3$.

release in the porcine model I, porcine model II, and human model, respectively $(t=210 \mathrm{~min})$. Zhu et al. ${ }^{62}$ showed approximately $15 \%$ release of FFA after the digestion of fish oil, Aarak et $a .^{63}$ showed a $20 \%$ release of FFA after the digestion of salmon muscle, and Larsson et al. ${ }^{24}$ showed a $40 \%$ release of FFA of total oil (mg) after the digestion of cod liver oil; all three using static pancreatic lipase based in vitro models; Larsson et al. ${ }^{24}$ with gastric lipase from Rhizopus oryzae added in the gastric step. Several factors determine the final lipolysis level, such as $\mathrm{pH},{ }^{64}$ presence of calcium, ${ }^{46,64}$ bile-salt levels, ${ }^{46}$ lipase activity, ${ }^{65}$ and droplet size of the emulsified oil. ${ }^{66}$ It is therefore no surprise that the porcine model I differed from the human digestion model and the porcine model II, although the basic settings were comparable.

When analysing the content of free EPA and DHA during and after the digestion, see Table 4, no major difference was seen between the three models in the gastric step $(t=$ $120 \mathrm{~min})$, except that the levels of free EPA and DHA in the porcine model I decreased twofold, compared to the other models. The detected levels of free EPA and DHA decreased in all models compared to what was found in the initial oil. This could be due to consumption of these FFA in the lipid oxidation reaction. Previous studies have shown that FFA are more susceptible to lipid oxidation than the intact triglycerides. ${ }^{67,68}$ Also, FFA can attract pro-oxidative metals and thus co-oxidize triglycerides. ${ }^{69}$ In the duodenal step $(t=210 \mathrm{~min})$, the lipolysis results differed between models in that a higher release of EPA was observed in the human model compared to the porcine models I and II (960\% increase during digestion, compared to $450 \%$ and $570 \%$, respectively). The same observation was made for DHA, with a higher release in the human model compared to the porcine models I and II $(230 \%$ increase during digestion, compared to $490 \%$ and $680 \%$, respectively). This supports the findings of Aarak et al. ${ }^{51}$ that there are differences in the release of EPA and DHA when using human versus porcine digestive enzymes. According to above, there could be a link between the release of free EPA/ DHA and the extent of lipid oxidation in the duodenal step. Larsson et al. ${ }^{24}$ found a link between total lipolysis and TBARS development in the gastric and duodenal step of a porcine static model. The importance of specific FFA released during digestion and its relation to lipid oxidation needs to be investigated further.

\section{The lipid oxidation products MDA, HHE, and HNE}

The lipid oxidation products MDA, HHE, and HNE were observed during gastric digestion in the human model, but none of the three products were identified in the gastric part of the porcine models (Fig. 3). During duodenal digestion, aldehydes were identified in both the human model and the porcine models I and II. A significantly $(p<0.05)$ higher accumulation of aldehydes occurred in the human model compared to the two porcine models, with the exception at $t=$ 150 min for HHE and HNE, where the differences were insignificant $(p>0.05)$. The aldehyde levels in all models decreased in the order: MDA $>$ HHE $>$ HNE. This is in accordance with the levels detected in human plasma samples, as reviewed by Pillon and Soulage, ${ }^{70}$ with MDA being found at the highest concentration, followed by HHE and HNE. Control samples without oil were run in parallel with the oil samples, see Table 5. These were analysed at the end of the gastric and intestinal step, in order to check how much the digestive components contributed to the lipid oxidation levels. The control samples showed that some lipid oxidation products were present in the digestive fluids alone, relative to each specific aldehyde and time point. The relatively high control values recorded at $120 \mathrm{~min}$ in human juices could indicate that the lipid oxidation reaction had already started in the human GI juices, which could explain the pronounced increase of recorded lipid oxidation products in the human model. In the porcine model II the HNE levels were larger in the control samples, than in oil-fortified samples, which could be due to the low levels of HNE detected ( $\mathrm{HNE}<0.01 \mu \mathrm{M})$. The lowest standard included to detect HNE was however even lower

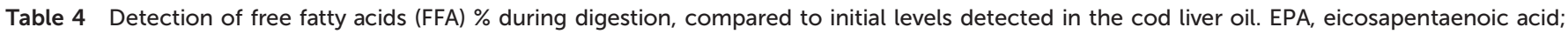
DHA, docosahexaenoic acid

\begin{tabular}{|c|c|c|c|c|c|c|}
\hline \multirow[b]{2}{*}{ FFA } & \multicolumn{3}{|c|}{ Gastric step (120 min) } & \multicolumn{3}{|c|}{ Duodenal step (210 min) } \\
\hline & Porcine model I & Porcine model II & Human model & Porcine model I & Porcine model II & Human model \\
\hline EPA (\%) & -60 & -30 & -40 & 450 & 570 & 960 \\
\hline DHA (\%) & -60 & -30 & -30 & 490 & 680 & 1230 \\
\hline
\end{tabular}


A

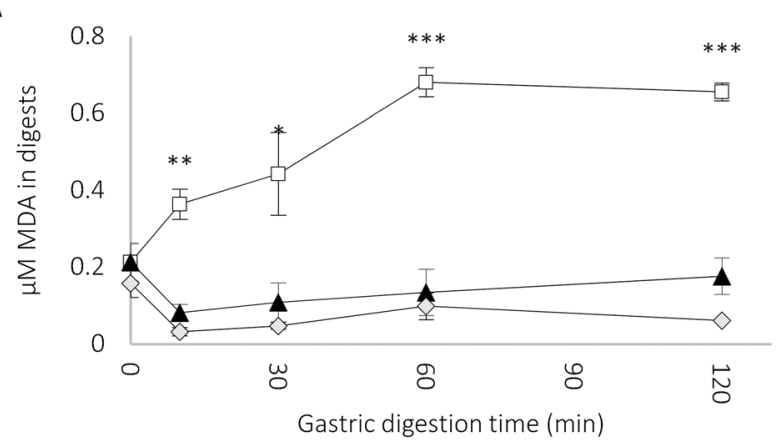

C

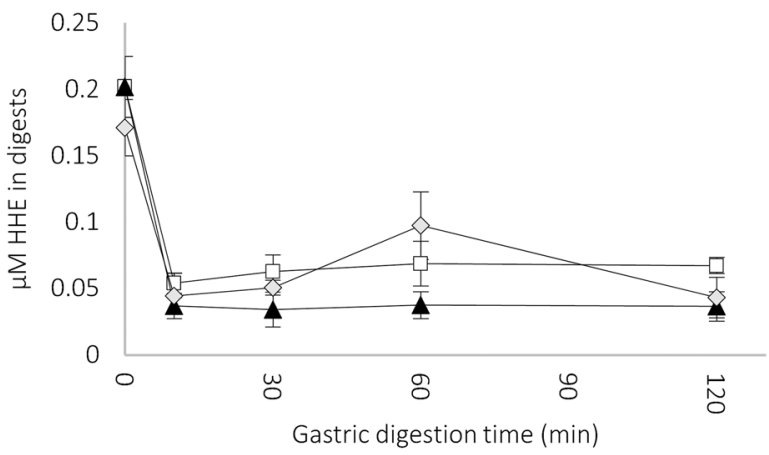

E

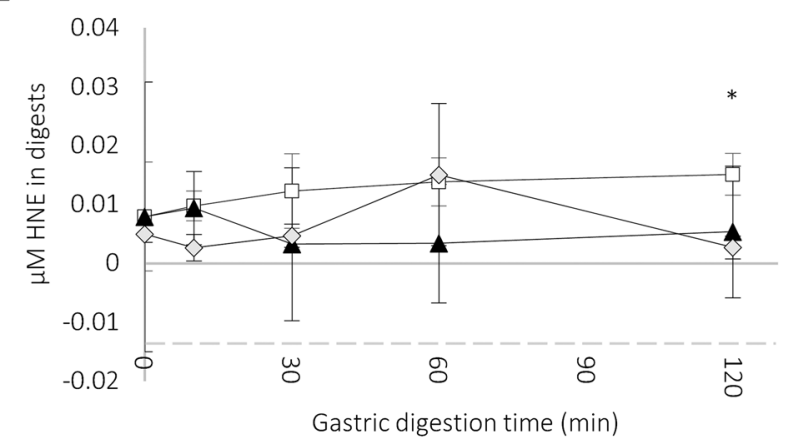

B

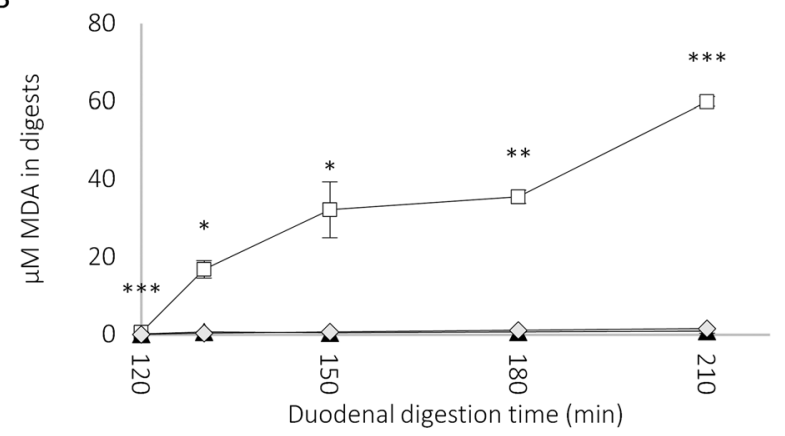

D

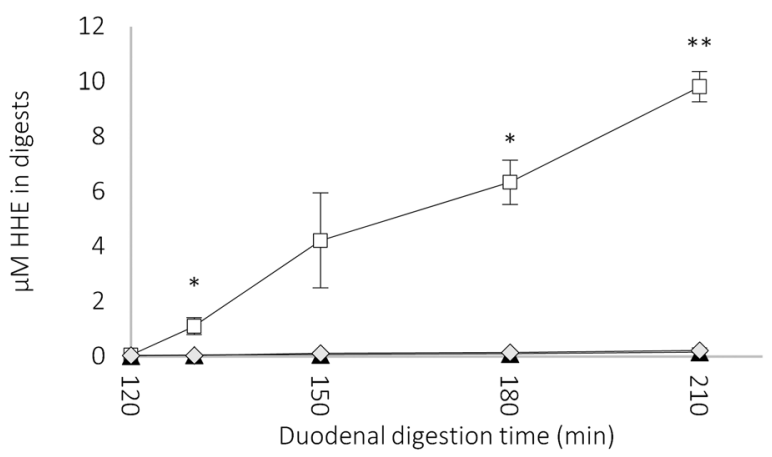

F

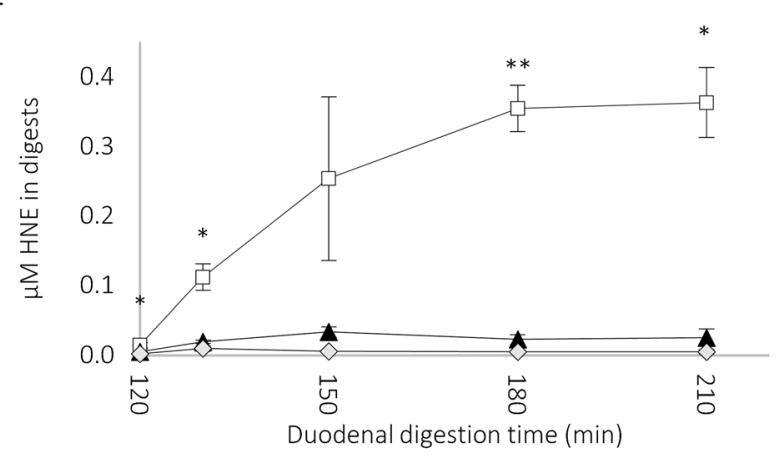

$$
\begin{aligned}
& \square-\text { Human digestion model } \\
& \neg \text { Porcine model I } \\
& \multimap-\text { Porcine model II }
\end{aligned}
$$

Fig. 3 Lipid oxidation products in the digests during gastric (0-120 min) and duodenal (120-210 min) digestion of cod liver oil. Malondialdehyde (MDA), 4-hydroxy-trans-2-hexenal (HHE), and 4-hydroxy-trans-2-nonenal (HNE). Gastric step is shown in panels (A) MDA, (C) HHE, and (E) HNE, and duodenal step is shown in panels (B) MDA, (D) HHE, and (F) HNE. Note the different scales on the $y$-axis in the panels. Error bars show SD, $n \geq 3$, except for samples from the porcine model I at time $130 \mathrm{~min}$, where $n=2$. Significant differences were seen between the human digestion model and both porcine models I and II, in the figures shown as ${ }^{*} p<0.05,{ }^{*} p<0.005$, and ${ }^{* * *} p<0.001$. In a few time points, a significant difference $(p<0.05)$ was seen between porcine models I and II as well; MDA ( $t=120 \mathrm{~min}, 130 \mathrm{~min}$, and $180 \mathrm{~min}), \mathrm{HHE}(t=180 \mathrm{~min})$, and HNE ( $t=150 \mathrm{~min})$.

Table 5 Levels of aldehydes reached in control samples (without oil) at the end of the gastric ( $t=120 \mathrm{~min}$ ) and intestinal $(t=210 \mathrm{~min})$ step. Data

\begin{tabular}{|c|c|c|c|c|c|c|}
\hline Aldehyde & $\begin{array}{l}\text { Porcine model I } \\
(120 \mathrm{~min})\end{array}$ & $\begin{array}{l}\text { Porcine model I } \\
(210 \mathrm{~min})\end{array}$ & $\begin{array}{l}\text { Porcine model II } \\
\text { (120 min) }\end{array}$ & $\begin{array}{l}\text { Porcine model II } \\
(210 \text { min) }\end{array}$ & $\begin{array}{l}\text { Human model } \\
\text { (120 min) }\end{array}$ & $\begin{array}{l}\text { Human model } \\
(210 \text { min })\end{array}$ \\
\hline MDA (\%) & 2.4 & 74 & 47 & 4.0 & 40 & 0.18 \\
\hline HNE (\%) & 1.7 & 57 & 180 & 180 & 37 & 9.7 \\
\hline
\end{tabular}
for the control samples are expressed as \% of the samples with oil. MDA, malondialdehyde; HHE, 4-hydroxy-trans-2-hexenal; HNE, 4-hydroxytrans-2-nonenal 
$(0.005 \mu \mathrm{M})$, and is still within the limits of quantification of the method.

We expected to see some lipid oxidation in the gastric step, however, this was not the case in any of the models. Our hypothesis was that the gastric environment, with low $\mathrm{pH}$, oxygen, and pro-oxidants present in the bolus, would induce lipid oxidation, according to the suggestions by Kanner and Lapidot $^{22}$ and Halliwell et $a l^{23}$ Also, Kristinova et $a l^{28}$ observed that lipid oxidation, measured by TBARS, PV, and oxygen uptake rate, was induced by the low $\mathrm{pH}$ itself, rather than the enzymes in the gastric juice. Lipid oxidation during in vitro digestion of cod liver oil, minced mullet muscle, and herring oil has also been previously observed in the gastric step. ${ }^{24,25,28}$ In these studies, less specific methods like TBARS, peroxide value (PV), and conjugated dienes were however used, and relatively low levels were detected. One possible explanation for the lack of lipid oxidation in the gastric step in our study could be the lack of gastric lipolysis, see Fig. 2. Lipase has sometimes been added in the gastric step in other in vitro digestion studies, e.g. in the study by Larsson et al. ${ }^{24}$ We did not add any gastric lipase in the porcine models, as gastric lipase is not a part of the standard protocol described by Minekus et $a l .{ }^{40}$ Even though the presence, levels and role of gastric lipase are still debated, since it has been discovered relatively recently, it is believed to contribute to $10-25 \%$ of the lipolysis during digestion. ${ }^{45}$ When Larsson et al. ${ }^{24}$ omitted the gastric enzymes and only incubated cod liver oil at $37{ }^{\circ} \mathrm{C}$ with the pH-cycle of the GI tract, no significant increase in the levels of TBARS was observed. This supports the theory that lipid oxidation in the gastric step is correlated to the presence of active gastric lipase. It is possible that the gastric lipase activity in the HGJ was lost during our collection/storage of the aspirates, since it is easily digested by pepsin at low $\mathrm{pH}$. Another possible explanation is that there were antioxidants present in the HGJ, which prevented the lipid oxidation reaction from being initiated. It is also possible that other parameters of the digestion models are important for the formation of lipid oxidation products, such as GI tract contraction/movements, or gastric digestion time.

To make the data comparable with what was reported by Larsson et $a .^{26}$ and Kenmogne-Domguia et $a l^{36}$ concentrations were recalculated from $\mu \mathrm{M}$ in the digests to $\mu \mathrm{M}$ in the lipid phase, see Table 6. Using LC with a diode array detector (DAD), Larsson et al. ${ }^{26}$ found an average level of total MDA that was 4 and 10 times higher compared to what was found in porcine models I and II in this study. This could be due to differences in the analysis method and in the in vitro digestion protocol, since the oil used was identical to the oil in our study. However, there were also differences in the used simulated electrolyte solutions, enzyme concentrations and bile-salt concentrations, and also in the detection methods, which could explain the different MDA levels found. KenmogneDomguia et $a l .^{36}$ studied lipid oxidation using stabilized marine oil emulsions; protein-stabilised emulsion (PSE) and phospholipid-stabilised emulsion (PpSE), and reported that the levels of MDA are in line with the levels found in this study, see Table 6. Larsson et al. ${ }^{26}$ measured HHE concentration by LC/APCI-MS during the digestion of cod liver oil with porcine enzymes and bile, and found levels similar to what was detected in all digestion models in our study. Kenmogne-Domguia et al. ${ }^{36}$ reported HHE concentrations in the digests, using PSE and PpSE, and the levels are 11-40 times higher compared to what was found in the porcine models of this study, but approximately 3.5 times lower than what was found in the human model, see Table 6 . The differences could be due to the addition of the pro-oxidant metmyoglobin in their in vitro digestion model, the use of a pre-emulsified oil mixture, or a higher oil : enzyme ratio. ${ }^{36}$ The HNE levels found in our models also differ with the HNE levels recorded in the two differently stabilized oil emulsions (PSE and PPSE) by Kenmogne-Domguia et al. ${ }^{36}$ being 50 times higher in their study compared to what was detected in this study. Apart from the mentioned metmyoglobin addition, this discrepancy is likely to be caused by the oil emulsions used by Kenmogne-Domguia et al. ${ }^{36}$ containing $10 \%$ n-6 FA, compared to $1 \%$ n- 6 FA in the cod liver oil used in this study. The maximum levels of aldehydes at 210 min observed in this study were 43, 203, and $5657 \mu \mathrm{mol}$ per $\mathrm{kg}$ lipid (MDA), 7.7, 27.2, and $951 \mu \mathrm{mol}$ per $\mathrm{kg}$ lipid (HHE), and 1.4, 0.82, and $44 \mu \mathrm{mol}$ per $\mathrm{kg}$ lipid (HNE) in the porcine model I, porcine model II, and human model, respectively. The low levels of HNE compared to MDA and HHE are in accordance with the low levels of LC n-6 PUFA in cod liver oil, 1.3 area $\%$ of detected total FA. ${ }^{42}$ On comparing this with the total amount of n-3 and n-6 PUFA in the oil, we obtained 1.9, 6.6, and $230 \mu \mathrm{mol}$ HHE per kg n-3 FA, and 0.02, 0.01 , and $0.6 \mu \mathrm{mol} \mathrm{HNE}$ per $\mathrm{kg} \mathrm{n}-6 \mathrm{FA}$, in the porcine model I, porcine model II and human model, respectively. This indicates that the n-3 PUFA in the cod liver oil was generally more susceptible towards oxidation compared to the n-6 PUFA. This could be due to a higher unsaturation degree in the n-3 PUFA

Table 6 Comparison between lipid oxidation levels reported in two different studies and this study, in the duodenal step, $t=180$ min. Values recalculated to be presented as $\mu \mathrm{mol} \mathrm{kg}^{-1}$. PSE, protein-stabilised emulsion; PpSE, phospholipid-stabilised emulsion; MDA, malondialdehyde; $\mathrm{HHE}$, 4-hydroxy-trans-2-hexenal; HNE, 4-hydroxy-trans-2-nonenal. n.a.: samples not analyzed

\begin{tabular}{|c|c|c|c|c|c|c|}
\hline Aldehyde & $\begin{array}{l}\text { Larsson } \\
\text { et al. }\end{array}$ & $\begin{array}{l}\text { Kenmogne-Domguia et al. }{ }^{36} \\
\text { (PSE) }\end{array}$ & $\begin{array}{l}\text { Kenmogne-Domguia et al. }{ }^{36} \\
\text { (PpSE) }\end{array}$ & $\begin{array}{l}\text { Porcine } \\
\text { model I }\end{array}$ & $\begin{array}{l}\text { Porcine } \\
\text { model II }\end{array}$ & $\begin{array}{l}\text { Human } \\
\text { model }\end{array}$ \\
\hline $\operatorname{MDA}\left(\mu \mathrm{mol} \mathrm{kg}{ }^{-1}\right)$ & 445 & 3300 & 7200 & 42 & 140 & 4465 \\
\hline
\end{tabular}


fraction compared to n-6 PUFA fraction in the cod liver oil, see Table 1. A comparison of the HHE and HNE levels to the total amount of free n-3 and n-6 PUFA detected after digestion $(t=$ $210 \mathrm{~min}$ ) supports this theory, and in the porcine model I, porcine model II, and human model we can report the formation of $0.75,2.1$, and $48 \mu \mathrm{mol}$ HHE per mg n-3 FA, and $0.14,0.074$, and $5.7 \mu \mathrm{mol}$ HNE per mg n-6 FA, respectively. This also indicates that there might be a correlation between the level of free n-3 and n-6 PUFA present and the susceptibility towards lipid oxidation.

We did not expect pronounced differences between the porcine and the human models with respect to MDA, HHE, and HNE after the duodenal step. Aarak et al. ${ }^{51}$ observed that the total amount of FFA released from salmon oil was similar to that when using a porcine and a human duodenal model, even if higher relative levels of EPA and DHA were released when using HDJ for digestion compared to porcine pancreatic enzymes. The same was observed in this study, and since FFA as well as more highly unsaturated PUFAs are known to be more susceptible to oxidation than esterified/more saturated FA, this could be an explanation for the difference in oxidation between the human and the porcine digestion models. To our knowledge, no previous study has looked at dissimilarities between a human and a porcine model from a lipid oxidation perspective, and there might be several factors influencing the higher occurrence of lipid oxidation during digestion with human GI juices, e.g. the presence of pro-oxidants, like iron. Preliminary analysis of minerals showed that trace metal ions, such as iron, were hardly detectable $(<0.5 \mathrm{ppm}$, data not shown). However, when analysing total haem pigment content, approximately 3 times higher haem pigment content in HDJ than in the other samples was seen (data not shown). This could be due to minor internal bleedings during aspiration, possibly caused by the insertion of the three-lumen tube for the collection of the HDJ. The result from the analysis of total haem pigment content could also however be due to colour interference by bilirubin or other bile complexes formed. This could explain the lack of correlation between iron and haem analyses. Further investigation of the cause of the different lipid oxidation levels in the two digestion models needs to be done.

Knowledge regarding the importance of lipid oxidation product formation during digestion is still limited. The biological role of $\alpha, \beta$-unsaturated aldehydes, such as MDA, HHE, and HNE, is extensively discussed, and the toxicity and reactivity of the products are being evaluated. MDA, HHE, and HNE can form Michael and Schiff base adducts with proteins, which could lead to various biological effects depending on the original role of the altered proteins. The reactivity of the $\alpha, \beta$-unsaturated aldehydes can also be directed towards phospholipids, causing major damage to biological membranes, where HNE appears to be more reactive than HHE. ${ }^{71}$ The reactivity towards cysteine-, lysine-, and histidine groups, by Michael addition followed by an attack on a nucleophilic group (e.g. in DNA), makes $\alpha, \beta$-unsaturated aldehydes quite genotoxic. $^{29,72} \mathrm{HHE}$ and $\mathrm{HNE}$ are known to be cytotoxic to

cells, and in the review by Pillon and Soulage, ${ }^{70} \mathrm{LC}_{50}$ levels of 20-60 $\mu \mathrm{M}$ after a long incubation time were reported for various animal and human cells; while $\mathrm{LC}_{50}$ for MDA was reported to be $\geq 600 \mu \mathrm{M}$. $^{70}$ These levels are higher than the levels reported in this study at $180 \mathrm{~min}$ digestion; the closest are the levels of HHE found in the human digestion model $(9.8 \mu \mathrm{M})$. Still, in vitro cellular damage has been reported at lower levels, a 70\% inhibition of the cell growth and induced apoptosis was for example observed by Cerbone et al. ${ }^{73}$ using human Caco- 2 cells and HNE $(1 \mu \mathrm{M})$. Bae et al. $^{74}$ reported the induction of HHE dose-dependent apoptosis in human epithelial renal proximal tubular cells, starting already at $10 \mu \mathrm{M}$ HHE. If the lipid oxidation products are absorbed, they could potentially cause systemic effects. In a review by Chapple et $a .^{75}$ different dose-dependent effects of HNE on in vitro cellular signalling were reported. Antioxidant defence and inflammatory response are enhanced at low HNE levels, however at higher doses, cell viability decreases and apoptosis is induced. ${ }^{75}$ The possible effects of lipid oxidation products on epithelial cells in the GI tract may differ and are still rather undiscovered. The ability of lipid oxidation products to be absorbed have been proven in vivo in rats, ${ }^{35}$ and also recently in our dynamic in vitro digestion study. ${ }^{76}$ However, to what extent this could happen in the human body, and what implications it would have on human health remains unclear.

\section{Conclusion}

In conclusion, reactive aldehydes (MDA, HHE, and HNE) were formed from cod liver oil during intestinal digestion using both human and porcine in vitro models. However, when comparing the human and porcine models with respect to oxidation, significantly higher generation of MDA, HHE, and HNE was observed during digestion with human GI enzymes and bile. The reason for the difference is still unknown; however, it may be due to qualitative differences in the release of FFA during digestion, or the presence of pro-oxidants like haem in the human GI juice. This finding may be important to bear in mind when using in vitro digestion models for studying lipid oxidation.

\section{Conflict of interest}

The authors declare no conflict of interest.

\section{Abbreviations}

APCI

BHT

DAD

DHA

DNPH

EDTA

EPA
Atmospheric pressure capillary ion

Butylated hydroxytoluene

Diode array detection

Docosahexaenoic acid

2,4-Dinitrophenylhydrazine

Ethylenediaminetetraacetic acid

Eicosapentaenoic acid 


$\begin{array}{ll}\text { FAME } & \text { Fatty acid methyl esters } \\ \text { FA } & \text { Fatty acids } \\ \text { GCA } & \text { Free fatty acids } \\ \text { GI } & \text { Gas chromatography-mass spectrometry } \\ \text { HDJ } & \text { Gastrointestinal } \\ \text { HGJ } & \text { Human duodenal juice } \\ \text { HHE } & \text { Human gastric juice } \\ \text { HNE } & \text { 4-Hydroxy-trans-2-hexenal } \\ \text { HPLC } & \text { High-performance liquid chromatography } \\ \text { LC/APCI-MS } & \text { Liquid chromatography/atmospheric pressure } \\ & \text { chemical ionization-mass spectrometry } \\ \text { LC n-3 PUFA } & \text { Long-chain n-3 polyunsaturated fatty acids } \\ \text { LC n-6 PUFA } & \text { Long-chain n-6 polyunsaturated fatty acids } \\ \text { MDA } & \text { Malondialdehyde } \\ \text { PSE } & \text { Protein-stabilised emulsion } \\ \text { PpSE } & \text { Phospholipid-stabilised emulsion } \\ \text { PV } & \text { Peroxide value } \\ \text { SPE } & \text { Solid phase extraction } \\ \text { TBARS } & \text { Thiobarbituric acid reactive substances } \\ \text { TEP } & \text { 1,1,3,3-Tetraethoxypropane } \\ & \end{array}$

\section{Acknowledgements}

The authors would like to thank Annette Almgren and Mehdi Abdullahi for laboratory work carried out on analysis of trace metal ions and haemoglobin. We would also like to thank Hanna Harrysson for technical assistance during the development of the LC/APCI-MS method for detecting MDA, HHE, and HNE. This work was financially supported by FORMAS (The Swedish Research Council for Environment, Agricultural Science and Spatial Planning, Project no 222-2012-1331).

\section{References}

1 L.-S. Kremmyda, E. Tvrzicka, B. Stankova and A. Zak, Biomed. Pap, 2011, 155, 195-218.

2 T. Nicholson, H. Khademi and M. H. Moghadasian, Food Funct., 2013, 4, 357-365.

3 C. J. Lavie, R. V. Milani, M. R. Mehra and H. O. Ventura, J. Am. Coll. Cardiol., 2009, 54, 585-594.

4 P. Nestel, P. Clifton, D. Colquhoun, M. Noakes, T. A. Mori, D. Sullivan and B. Thomas, Heart, Lung Circ., 2015, 24, 769-779.

5 P. C. Calder, Br. J. Clin. Pharmacol., 2013, 75, 645-662.

6 S. Lorente-Cebrián, A. V. Costa, S. Navas-Carretero, M. Zabala, L. Laiglesia, J. A. Martínez and M. MorenoAliaga, J. Physiol. Biochem., 2015, 1-9, DOI: 10.1007/s13105015-0395-y.

7 P. C. Calder, Am. J. Clin. Nutr., 2006, 83, S1505-1519S.

8 J. de Aguiar Pastore Silva, M. Emilia de So Fabre and D. L. Waitzberg, Clin. Nutr., 2015, 34, 359-366.

9 V. C. Vaughan, M. R. Hassing and P. A. Lewandowski, Br. J. Cancer, 2013, 108, 486-492.
10 R. A. Murphy, M. Mourtzakis and V. C. Mazurak, Curr. Opin. Clin. Nutr. Metab. Care, 2012, 15, 246-251.

11 E. C. Rizos, E. E. Ntzani, E. Bika, M. S. Kostapanos and M. S. Elisaf, JAMA, J. Am. Med. Assoc., 2012, 308, 1024-1033.

12 L. Hooper, R. L. Thompson, R. A. Harrison, C. D. Summerbell, A. R. Ness, H. J. Moore, H. V. Worthington, P. N. Durrington, J. P. T. Higgins, N. E. Capps, R. A. Riemersma, S. B. J. Ebrahim and G. D. Smith, Risks and benefits of omega 3 fats for mortality, cardiovascular disease, and cancer: systematic review, Br. Med. J., 2006, 332(7544), 752760.

13 R. Chowdhury, S. Stevens, D. Gorman, A. Pan, S. Warnakula, S. Chowdhury, H. Ward, L. Johnson, F. Crowe, F. B. Hu and O. H. Franco, Br. Med. J., 2012, 345, e6698.

14 T. A. B. Sanders, Proc. Nutr. Soc., 2014, 73, 73-79.

15 K. H. Weylandt, S. Serini, Y. Q. Chen, H.-M. Su, K. Lim, A. Cittadini and G. Calviello, BioMed Res. Int., 2015, 2015, 143109.

16 N. S. Kelley, Y. Yoshida and K. L. Erickson, Metab. Syndr. Relat. Disord., 2014, 12, 403-415.

17 R. Turner, C. H. McLean and K. M. Silvers, Nutr. Res. Rev., 2006, 19, 53-62.

18 B. B. Albert, D. Cameron-Smith, P. L. Hofman and W. S. Cutfield, BioMed Res. Int., 2013, 2013, 8.

19 J. Kanner, Mol. Nutr. Food Res., 2007, 51, 1094-1101.

20 C. Strobel, G. Jahreis and K. Kuhnt, Lipids Health Dis., 2012, 11, 144.

21 E. Arab-Tehrany, M. Jacquot, C. Gaiani, M. Imran, S. Desobry and M. Linder, Trends Food Sci. Technol., 2012, 25, 24-33.

22 J. Kanner and T. Lapidot, Free Radical Biol. Med., 2001, 31, 1388-1395.

23 B. Halliwell, K. Zhao and M. Whiteman, Free Radical Res., 2000, 33, 819-830.

24 K. Larsson, L. Cavonius, M. Alminger and I. Undeland, J. Agric. Food Chem., 2012, 60, 7556-7564.

25 R. Maestre, J. D. Douglass, S. Kodukula, I. Medina and J. Storch, J. Nutr., 2013, 143, 295-301.

26 K. Larsson, K. Istenič, T. Wulff, R. Jónsdóttir, H. Kristinsson, J. Freysdottir, I. Undeland and P. Jamnik, J. Sci. Food Agric., 2015, 95(15), 3096-3106.

27 M. Gobert, D. Remond, M. Loonis, C. Buffiere, V. SanteLhoutellier and C. Dufour, Food Funct., 2014, 5, 2166-2174.

28 V. Kristinova, I. Storrø and T. Rustad, Food Chem., 2013, 141, 3859-3871.

29 H. Esterbauer, R. J. Schaur and H. Zollner, Free Radical Biol. Med., 1991, 11, 81-128.

30 D. Del Rio, A. J. Stewart and N. Pellegrini, Nutr., Metab. Cardiovasc. Dis., 2005, 15, 316-328.

31 M. Guichardant, S. Bacot, P. Molière and M. Lagarde, Prostaglandins, Leukotrienes Essent. Fatty Acids, 2006, 75, 179-182.

32 F. J. G. M. Van Kuijk, L. L. Holte and E. A. Dratz, Biochim. Biophys. Acta, Lipids Lipid Metab., 1990, 1043, 116-118.

33 W. A. Pryor and N. A. Porter, Free Radical Biol. Med., 1990, 8, 541-543. 
34 E. K. Long and M. J. Picklo Sr, Free Radical Biol. Med., 2010, 49, 1-8.

35 M. Awada, C. O. Soulage, A. Meynier, C. Debard, P. Plaisancié, B. Benoit, G. Picard, E. Loizon, M.-A. Chauvin, M. Estienne, N. Peretti, M. Guichardant, M. Lagarde, C. Genot and M.-C. Michalski, J. Lipid Res., 2012, 53, 2069-2080.

36 H. B. Kenmogne-Domguia, S. Moisan, M. Viau, C. Genot and A. Meynier, Food Chem., 2014, 152, 146-154.

37 R. Mendes, C. Cardoso and C. Pestana, Food Chem., 2009, 112, 1038-1045.

38 E. Goicoechea, E. F. A. Brandon, M. H. Blokland and M. D. Guillén, Food Chem. Toxicol., 2011, 49, 115-124.

39 E. Grosjean, D. Grosjean, P. G. Green and J. M. Hughes, Agilent Technologies, 2000, No. 5986-8850E.

40 M. Minekus, M. Alminger, P. Alvito, S. Ballance, T. Bohn, C. Bourlieu, F. Carriere, R. Boutrou, M. Corredig, D. Dupont, C. Dufour, L. Egger, M. Golding, S. Karakaya, B. Kirkhus, S. Le Feunteun, U. Lesmes, A. Macierzanka, A. Mackie, S. Marze, D. J. McClements, O. Menard, I. Recio, C. N. Santos, R. P. Singh, G. E. Vegarud, M. S. J. Wickham, W. Weitschies and A. Brodkorb, Food Funct., 2014, 5, 11131124.

41 E. K. Eriksen, H. Holm, E. Jensen, R. Aaboe, T. G. Devold, M. Jacobsen and G. E. Vegarud, Br. J. Nutr., 2010, 104, 374381.

42 R. Jónsdóttir, M. Geirsdóttir, P. Y. Hamaguchi, P. Jamnik, H. G. Kristinsson and I. Undeland, J. Sci. Food Agric., 2015, DOI: $10.1002 /$ jsfa.7328.

43 E. K. Ulleberg, I. Comi, H. Holm, E. B. Herud, M. Jacobsen and G. E. Vegarud, Food Dig., 2011, 2, 52-61.

44 H. Holm, Å. Krogdahl and L. E. Hanssen, J. Nutr., 1988, 118, 521-525.

45 J.-C. B. N'Goma, S. Amara, K. Dridi, V. Jannin and F. Carrière, Ther. Delivery, 2011, 3, 105-124.

46 N. H. Zangenberg, A. Müllertz, H. G. Kristensen and L. Hovgaard, Eur. J. Pharm. Sci., 2001, 14, 115-122.

47 M. Repetto, J. Semprine and A. Boveris, Lipid Peroxidation: Chemical Mechanism, Biological Implications and Analytical Determination, in Lipid Peroxidation, ed. A. Catala, InTech, 2012, DOI: 10.5772/45943.

48 G. Márquez-Ruiz, F. Holgado and J. Velasco, in Food Oxidants and Antioxidants, CRC Press, 2013, pp. 79-114, DOI: 10.1201/b15062-5.

49 M. Fredrikson, N.-G. Carlsson, A. Almgren and A.-S. Sandberg, J. Agric. Food Chem., 2002, 50, 59-65.

50 H. C. Hornsey, J. Sci. Food Agric., 1956, 7, 534-540.

51 K. E. Aarak, B. Kirkhus, H. Holm, G. Vogt, M. Jacobsen and G. E. Vegarud, Br. J. Nutr., 2013, 110, 1402-1410.

52 E. G. Bligh and W. J. Dyer, Can. J. Biochem. Physiol., 1959, 37, 911-917.

53 C. Lee, B. Trevino and M. Chaiyawat, J. AOAC Int., 1996, 79, 487-492.
54 M. A. Kaluzny, L. A. Duncan, M. V. Merritt and D. E. Epps, J. Lipid Res., 1985, 26, 135-140.

55 L. R. Cavonius, N.-G. Carlsson and I. Undeland, Anal. Bioanal. Chem., 2014, 406, 7313-7322.

56 N. Deighton, W. J. Magill, D. H. Bremner and E. E. Benson, Free Radical Res., 1997, 27, 255-265.

57 R. Andreoli, P. Manini, M. Corradi, A. Mutti and W. M. A. Niessen, Rapid Commun. Mass Spectrom., 2003, 17, 637-645.

58 T. Sakai, Y.-i. Matsushita, K. Sugamoto and K. Uchida, Biosci., Biotechnol., Biochem., 1997, 61, 1399-1400.

59 E. L. McConnell, H. M. Fadda and A. W. Basit, Int. J. Pharm., 2008, 364, 213-226.

60 L. Kalantzi, K. Goumas, V. Kalioras, B. Abrahamsson, J. B. Dressman and C. Reppas, Pharm. Res., 2006, 23, 165176.

61 J. Dressman, G. Amidon, C. Reppas and V. Shah, Pharm. Res., 1998, 15, 11-22.

62 X. Zhu, A. Ye, T. Verrier and H. Singh, Food Chem., 2013, 139, 398-404.

63 K. E. Aarak, N. M. Rigby, B. Kirkhus, L. J. Salt, S. Sahlstrom, G. B. Bengtsson, G. E. Vegarud and A. R. Mackie, Food Funct., 2013, 4, 1819-1826.

64 H. Y. Eldemnawy, A. Wright and M. Corredig, Food Dig., 2015, 6(1), 10-18.

65 B. Lorrain, O. Dangles, M. Loonis, M. Armand and C. Dufour, J. Agric. Food Chem., 2012, 60, 9074-9081.

66 M. Armand, B. Pasquier, M. André, P. Borel, M. Senft, J. Peyrot, J. Salducci, H. Portugal, V. Jaussan and D. Lairon, Am. J. Clin. Nutr., 1999, 70, 1096-1106.

67 R. L. Shewfelt, J. Food Biochem., 1981, 5, 79-100.

68 T. D. Labuza, CRC Crit. Rev. Food Technol., 1971, 2, 355405.

69 T. Waraho, D. J. McClements and E. A. Decker, Food Chem., 2011, 129, 854-859.

70 N. J. Pillon and C. O. Soulage, Lipid Peroxidation byProducts and the Metabolic Syndrome, in Lipid Peroxidation, ed. A. Catala, InTech, 2012, DOI: 10.5772/46019.

71 S. Bacot, N. Bernoud-Hubac, N. Baddas, B. Chantegrel, C. Deshayes, A. Doutheau, M. Lagarde and M. Guichardant, J. Lipid Res., 2003, 44, 917-926.

72 R. M. LoPachin and T. Gavin, Chem. Res. Toxicol., 2014, 27, 1081-1091.

73 A. Cerbone, C. Toaldo, S. Laurora, F. Briatore, S. Pizzimenti, M. U. Dianzani, C. Ferretti and G. Barrera, Free Radical Biol. Med., 2007, 42, 1661-1670.

74 E. H. Bae, S. Cho, S. Y. Joo, S. K. Ma, S. H. Kim, J. Lee and S. W. Kim, Nephrol., Dial., Transplant., 2011, 26, 38663873.

75 S. J. Chapple, X. Cheng and G. E. Mann, Redox Biol., 2013, 1, 319-331.

76 K. Larsson, H. Harrysson, R. Havenaar, M. Alminger and I. Undeland, Food Funct., 2016, DOI: 10.1039/C5FO01401H. 